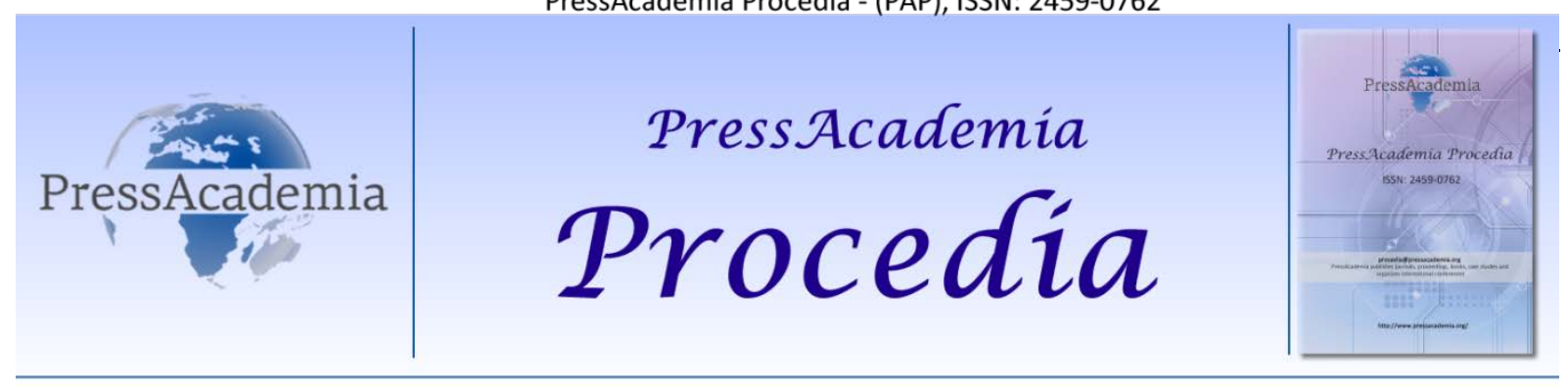

Global Business Research Congress (GBRC), May 26-27, 2016, Istanbul, Turkey.

\title{
ASSESING THE EFFECT OF ENVIRONMENTAL MANAGEMENT AND LEAN PRODUCTION SYSTEMS ON FIRM PERFORMANCE
}

\section{DOI: 10.17261/Pressacademia.2016118667}

\author{
M. Sahin Gok ${ }^{1}$, Tugkan Arici ${ }^{2}$ \\ ${ }^{1}$ Gebze Technical University, sahingok@gtu.edu.tr \\ ${ }^{2}$ Gebze Technical University, tarici@gtu.edu.tr
}

\begin{abstract}
Environmental management has increasingly become one of the key concerns of companies for effective utilization of their limited resources. Growing sensibility towards environmental issues mainly leads to increased costs for the companies and thus might reduce profitability. However lean production systems propose an alternative approach to improve both effectiveness and profitability by eliminating waste and non-value added transactions/activities. The main purpose of this study is to empirically analyze the relationship between environmental management and lean production systems as well as their effect on firm performance. The moderating effect of technological orientation between environmental management and firm performance is also examined. The model presented provides implications for both empirical research and company management in practice. Expected findings focus less on general statistical correlations and more on causal relationships of environmental management, lean production and firm performance. Consequently, implications and future research directions are also discussed according to the results.
\end{abstract}

Keywords : Environmental management, lean production systems, firm performance, technological orientation JEL Codes: 013, 014, M10

\section{YALIN ÜRETIM SISTEMLERININ VE ÇEVRESEL YÖNETIMIN FIRMA PERFORMANSINA ETKILERININ DEĞERLENDIRILMESi}

\section{ÖZET}

Günümüzde kıııtı kaynakların etkin kullanımı konusunda çevresel yönetim, şirketlerin birincil öncelikleri haline gelmiştir. Bu durumun doğal bir sonucu olarak şirketlerin maliyetleri yükselmekte ve kar oranları azalabilmektedir. Bu noktada, atıkların ve değer katmayan faaliyetlerin elimine edilmesi temel prensibine dayalı yalın üretim sistemleri, karlıık ve etkinliği artırabilecek alternatif bir yaklaşımı ortaya koyması bakımından önem taşımaktadır. Bu çalışma kapsamında da çevresel yönetim ile yalın üretim sistemlerinin ve firma performansı ilişkisinin ampirik olarak analiz edilmesi amaçlanmaktadır. Ayrıca teknolojik yönelimin çevresel yönetim ve firma performansı ilişkisindeki moderatör etkisi de çalışma kapsamında analiz edilmekte ve bu anlamda ilgili literatüre katkıda bulunulması hedeflenmektedir. Çalışma kapsamında önerilip analiz edilen model gerek alandaki diğer araştırmalara gerekse de şirketlere öneriler sunmakta ve sonuçlar genel istatistiki değerleri ortaya koymanın ötesinde, çevresel yönetim, yalın üretim ve firma performansı arasındaki uygulamaya dönük ilişkileri yönetsel anlamda tanımlamaktadır.

Anahtar Kelimeler: Çevresel Yönetim, Yalın Üretim Sistemleri, Firma Performansı, Teknolojik Yönelim JEL Kodları: 013, 014, M10 


\section{GíRiş}

Küresel ekonomik düzenin ortaya çıkmasıyla birlikte işletmeler açısından da artık sınır denilen bir kavram kalmamıştır. Firmaların piyasaya sundukları ürün veya hizmetlerin hammaddesi veya yarı mamul maddesi farklı ülkelerden tedarik edilebilir, montaj aşaması bambaşka bir ülkede gerçekleştirilebilir ve hatta firmanın sunduğu ürün veya hizmet, kıtalar arası pazarlarda lider konumda olabilir.

Rekabet koşullarının günümüzde gittikçe daha da zorlaştığını göz önüne alırsak, firmaların faaliyetlerini sürdürebilmesi için rekabet avantajı sağlayacak stratejiler geliştirmeleri kaçınılmaz hale gelmiştir. Sektöre yeni giren firmaların pazarda tutunabilmesi ve piyasada hâlihazırda var olan firmaların da pazar paylarını koruması ya da pazar paylarını daha da arttırabilmesi için Porter'ın jenerik (Bordean, et.al., 2011) stratejiler olarak tanımlamış olduğu üç temel stratejiden bir veya bir kaçını seçmeleri gerekmektedir. Farklılaştırma, Maliyet Avantajı ve Cevap Verebilme stratejilerinden hangisi seçilirse seçilsin, firmalar açısından günümüz küresel rekabet seviyesi göz önüne alındığında maliyet odaklı stratejiler ile rekabet stratejilerinin desteklenmesi kaçınılamaz bir zorunluluk konumundadır.

Bu çalışma kapsamında, çevresel yönetim ve yalın üretim sistemleri arasındaki ilişkiyi ampirik olarak analiz etmeyi ve çevresel yönetim ile firma performansı arasındaki ilişkiye teknolojik yönelimin etkisinin de incelenmesi amaçlamaktadır. Özellikle teknolojik ilerlemelere bağlı olarak israf önleyici uygulamaların geliştirilmesi, katma değerli faaliyetlerin daha etkin bir şekilde uygulanmasına bağlı olarak yalın üretim sistematiğinin gelişim sağlayacağını ve bu gelişimin de çevresel yönetim üzerinde pozitif etkisi bulunacağı varsayımı yapılarak teknolojik yönelimin moderatör etkisinin, firma performansı üzerinde görülebileceğini önermekteyiz. Çevresel yönetimde teknolojik oryantasyonun etkisini analiz etmesi bakımından bu çalışma ilgili literatüre katkıda bulunmaktadır.

Çalışmanın ikinci bölümünde araştırma yöntemi ve metot açıklandıktan sonra üçüncü bölümde analiz ve sonuçlar detaylandırılmaktadır. Son bölümde de ise çalışma bulguları değerlendirilmekte ve gelecek araştırma önerileri ile uygulayıcılara öneriler sunulmaktadır.

\section{LITERATÜR TARAMASI}

Küreselleşme ve hızla ilerleyen teknolojik seviyeye bağlı olarak müşteri beklenti ve ihtiyaçları da yükselen bir ivme ile çeşitlenmektedir. Bu noktada geleneksel bakış açısıyla değerlendirilebilecek üretim unsurları olan toprak, iş gücü ve sermaye kavramları da değişiklik göstermekte ve kısıtlı kaynakların etkin kullanımı gibi önemli bir parametre uygulamada kendisine yer bulmaktadır. Ancak söz konusu kısıtlı (doğal) kaynaklarda tükenme noktasına doğru ilerlemekte ve etkin kullanım felsefesi çok daha yüksek bir öneme haiz bulunmaktadır.

Diğer taraftan, çevresel konularda önlemler almaya başlayan firmalar için bu durum, maliyetlerinde artışlara neden olmuştur ve karlılık oranında azalışlar meydana gelmiştir. Ancak yalın üretim sistemleri, hem karlılığı hem de etkinliği arttırdığı gibi, israf ve değer katmayan işlemleri de ortadan kaldırdığı için maliyet avantajı sağlar bu da beraberinde kar artışı getirmektedir ve daha az kaynak kullanımını sayesinde çevreye daha fazla duyarlılık göstermektedir (Ertürk ve Özçelik, 2008).

1950'li yıllarda ilk defa Toyota fabrikasında denenen yalın üretim tekniğinin yaklaşık 60 yıllık bir geçmişi bulunmaktadır (Aziz \& Hafez, 2013). Yalın üretim felsefesinin ders kitaplarından çıkarak pratik uygulamalarda yer almasının altında yatan en önemli sebepte budur. Yalın üretim sistematiği ile süreçlerini organize eden işletmeler; en az kaynakla, en az maliyetle, en az insan emeğiyle, en az süreyle, bol çeşitli ve en kaliteli ürünü en uygun fiyatla müşterilerine sunabilmektedir (Ertürk ve Özçelik, 2008).

90'lı yıllarda çevresel yönetim ile ilgili çalışmalar yapılırken, yalın üretim ile çevresel yönetim arasında bir ilişki olabileceği fikri ortaya çıktı. Ancak bu yıllardaki çalışmalarda ikili ilişki net bir şekilde açıklanamadı. 2000'li yıllara gelindiğinde ise, bu iki sistemin arasındaki ilişkiyi açıklayabilmek adına yapılan çalışmalar hız kazandı ve ilk defa iki sistem arasındaki ilişki tam olarak ortaya konuldu (Chiarini, 2014).

Andrew A. King ve Michael J. Lenox, ABD’deki şirketleri örneklem alarak yaptıkları “Lean and Green an Empirical Examination of The Relationship Between Lean Production and Environmental Performance" isimli 
çalışmalarında yalın üretim ile çevresel yönetim arasındaki ilişkiyi kanıtlayabildi. Bu çalışmaya göre yalın üretim sistemi; kirliliği, kirlilik maliyetlerini ve israfları azaltabilmektedir (Chiarini, 2014).

Andrew A. King ve Michael J. Lenox, 1991 ile 1996 yılları arasında ABD'de kurulmuş olan 17.499 adet üretim firmasının çevresel performansını ampirik analizler gerçekleştirerek analiz ettiler. Çalışmalarının sonucunda, yalın üretim felsefesinin kirliliği önlemede ve daha az emisyon oranı yaymada ilişkili olduğunu kanıtlamışlardır. King ve Lenox'a göre, “Lean is Green”dir. Yani yalın üretim yeşil üretimdir (King and Lenox, 2001).

\section{VERI VE YÖNTEM}

Araştırma veri toplama aşamasında anket yöntemi kullanılmıştır. Bu kapsamda, basılı ve elektronik anket formu doldurma yöntemleri birlikte uygulanmıştır. Basılı anket doldurma yöntemi ile 100 firmaya ulaşılış ancak bunlardan 76 tanesinden anket geri dönüşü sağlanabilmiştir. Yapılan incelemeler sonunda bu 76 anketten 55 tanesi analiz sürecine katılması uygun görülmüş olup geri kalan 11 adet anket eksik veri girişine bağlı olarak analizlere dahil edilmemiştir. Anket formlarını elden teslim edemediğimiz firmalara ise, elektronik anketin linki gönderilmiştir. Anketimize toplam 70 adet geri dönüş yapılmış olup, bunların 53 tanesi incelemeye uygun görülmüştür. Bu anlamda araştırma toplam 108 anket verisi ile gerçekleştirilmiştir.

Araştırmaya dahil olan firmaların sektörleri incelendiğinde karşımıza geniş bir sektörel dağılım çıkmaktadır. Hizmet sektörleri içerisinde; GSM operatörleri, bankalar ve sigorta firmaları ile denetim firmaları bulunmaktadır. Anketimize katılan üretim sektöründe faaliyet gösteren firmalar incelendiğinde; boya ve kimyasal üretimi yapan firmalar, otomotiv, gazlı içecek, inşaat, medikal malzeme üretimi sektörlerinde faaliyet gösteren birçok firma bulunmaktadır.

Yalın üretim sistemi, çevresel performans ve firma performansı ilişkisinin teknolojik yönelim bağlamında analiz edildiği bu çalışmadaki temel araştırma soruları şu şekildedir: (i) Yalın üretim ve çevresel yönetim ile firma performansı arasında doğrudan yada dolaylı bir etki bulunmakta mıdır?, (ii) Teknolojik yönelik çevresel yönetim ve firma performansı ilişkisine etki etmekte midir? Söz konusu araştırma sorularını test etmeye yönelik olarak geliştirilmiş olan hipotezler aşağıda verilmektedir.

$\mathrm{H}_{1}$ : Yalın üretim sistemi, firma performansına pozitif yönlü etki etmektedir.

$\mathrm{H}_{2}$ : Çevresel Yönetim, firma performansına pozitif yönlü etki etmektedir.

$\mathrm{H}_{3}$ : Çevresel yönetim ile firma performansı ilişkisine, teknolojik yönelim moderatör değişken olarak etkilemektedir.

Yukarıda tanımlanmış olan hipotezleri test edebilmek için öncelikle ölçeklerin güvenilirlik analizleri gerçekleştirilmiş ve tüm ölçekler 0.70 güven düzeyinin üzerinde sonuçlara sahip olduğu görülmüştür. Hipotez analizleri kapsamında ise öncelikle çoklu regresyon analizi uygulanmış ve yalın üretim sistemi ile çevresel yönetimin firma performansına etkileri analiz edilmiştir. Sonrasında ise aşamalı regresyon analizi uygulanarak teknolojik yönelimin moderatör etkisi, çevresel yönetim ve firma performansı ilişkisi üzerinde test edilmiştir. Korelasyon analizi ile ise yalın üretim sistemleri ile çevresel yönetim ilişkisi test edilmiştir.

\section{BULGULAR VE TARTIŞMA}

Birinci aşama analizler kapsamında yalın üretim sistemlerinin ve çevresel yönetimin, firma performansı üzerindeki etkisi incelenmiştir. Bu analizlerdeki temel amaç bağımlı değişken olarak tanımlanmış olan firma performansı üzerinde bağımsız değişkenlerin etkisinin analiz edilmesidir. Yalın üretim sistemlerinin ve çevresel yönetimin firma performansı üzerindeki etkisini değerlendirmek için uygulanan çoklu regresyon analizi sonuçları Tablo.2'de Model.1'de görülmektedir. Moderatör etkiyi analiz edebilmek için aşamalı regresyon analizi aşağıdaki açıklandığı şekilde gerçekleştirilmiş ve sonuçları Tablo.2, Model.2'de verilmiştir.

1. Moderatör etkinin olmadığı regresyon modelinin uygulanması [Tablo.2, Model.1]

2. Moderatör ilişkinin eklendiği regresyon modelinin uygulanması (orijinal modele moderatör değişkenin eklenmiş hali) [Tablo.2, Model.2] 
Tablo 2: Regresyon Analizi Sonuçları

\begin{tabular}{llccc}
\hline Model & & Etki $(\beta)$ & $\begin{array}{c}\text { Standart } \\
\text { Hata }\end{array}$ & Anlamlıık \\
\hline 1 & Yalın Üretim & 0.241 & 0.097 & $0.000^{* *}$ \\
& Çevresel Yönetim & 0.184 & 0.038 & $0.000^{* *}$ \\
& Teknoloji Yönelimi & -0.411 & 0.007 & 0.697 \\
& & & & \\
2 & Yalın Üretim & 0.483 & 0.063 & $0.052^{*}$ \\
& Çevresel Yönetim & 0.609 & 0.019 & $0.048^{*}$ \\
& Teknoloji Yönelimi & 0.385 & 0.184 & 0.421 \\
& Moderatör Değişkeni & 0.097 & 0.031 & $0.078^{*}$ \\
\hline
\end{tabular}

Model 1: R2 değeri: 0.382 , olasılık: $0.000 * *$

Model 2: R2 değeri: 0.417 , olasılık: $0.000^{* *}$

$* \mathrm{p}<0.10$ seviyesinde anlamlı

$* * p<0.01$ seviyesinde anlamlı

Regresyon analizi sonuçlarına göre yalın üretim sistemlerinin ve çevresel yönetimin firma performansı üzerinde anlamlı ve pozitif etkileri bulunduğu sonucuna ulaşılıştır ( $\beta 1=0.241$ ve $\beta 2=0.184$ ). Buna bağlı olarak araştırma kapsamında geliştirilmiş olan $\mathrm{H} 1$ ve $\mathrm{H} 2$ hipotezleri kabul edilmiştir. Bunun yanında araştırma kapsamındaki bir diğer hipotezi oluşturan teknolojik yönelimin çevresel yönetim ile firma performansı ilişkisini etkilemesi de aşamalı regresyon analizi ile test edilmiş ve moderatör değişkenin modele katılımını gösteren Model.2'de görüldüğü gibi ( $\beta 3=0.421$ ile anlamsızken; $\beta 4=0.097$ değeri ile 0.10 seviyesinde anlamlı) H3 hipotezi de desteklenmiştir. Diğer bir ifade ile teknolojik yönelimin doğrudan firma performansına bir etkisi bulunmazken, çevresel yönetimin firma performansı üzerindeki etkisini pozitif yönlü olarak etkilemektedir.

\section{SONUÇ}

Analiz sonuçlarında da açık bir şekilde görüldüğü gibi firmalar katma değer yaratmayan faaliyetlerden vazgeçerek verimliliği arttırma çalışmaları gerçekleştirdiklerinde bir diğer ifadeyle yalın üretim uygulamalarına önem verdiklerinde kümülatif anlamda firma performanslarını artırdıkları sonucuna ulaşılmıştıı. Bu sonuç firmaların geleneksel bakış açıları ile yönetim mantığını değiştirmeleri gerektiği ve yalın üretim sistemleri gibi yenilikçi uygulamalara daha fazla önem vermeleri gerektiğini ortaya koymaktadır. Bu şekilde yalın üretim sisteminin kurulumu konusunda ilk yatırım maliyeti olarak değerlendirilebilecek olan belirli bir maliyet artışı yada kaynak verimliliği düşüşü görülse de (Lewis, 2000) nihai firma performansında yaşanacak ve sürdürülebilir yapıdaki yükselişsin kazanımları orta-uzun vadede daha yüksek olması beklenmektedir.

Benzer bir sonuç da çevresel yönetime verilen önem konusunda ortaya çıkmıştır. Firmalar çevresel yönetime verdikleri önemleri arttırdıklarında ve çevreye duyarlı üretim sistemlerine daha fazla önem verdiklerinde firma performansında yükselme yaşama potansiyeline sahip bulunmaktadırlar. Bunun yanında çevresel yönetime verilen önem derecesinin firmaların müşterilerine sunmuş olduğu ürün ve hizmetlerde de gerek algısal gerekse de somut bir takım katma değerleri de bulunabilecektir (Ay ve Ecevit 2005), Dolayısıyla çevresel yönetime verilen önem aynı zamanda firmanın tüketici nezdindeki değerini de artııması ve önemli bir pazarlama argümanı olarak kullanılması beklenmektedir. Ayrıca küresel anlamdaki çevreye yönelik bilinç seviyesinin artmasına bağlı olarak, müşterilerin ürün ve hizmetlerden de beklentileri bu anlamda farklılık göstermekte ve daha çevreci firmalar günümüzde önemli bir rekabet avantajına da sahip olabilmektedirler (Chavan, 2005). Bu anlamda çevresel yönetimin uygulamalarının firmalara maliyet oluşturmanın ötesinde önemli ekonomik kazanımlar sağlaması beklenmektedir.

Çalışma kapsamında ulaşılan ilginç bulgulardan birisi de teknolojik yönelim, çevresel yönetim ve firma performansı ilişki arasındadır. Çevresel yönetim uygulamalarına önem veren işletmelerin, firma 
performanslarını arttırdığı sonucuna ek olarak teknolojik anlamda yeniliklere önem vermenin de çevresel yönetim ve firma performansı ilişkisini olumlu anlamda etkilediği, diğer bir ifadeyle firma performansını daha fazla yükselttiği sonucuna ulaşımışıı. Bu durum firmaların çevresel yönetim konusundaki duyarlııklarını bilimsel yöntemler gelişen teknolojik seviyeye uygun yenilikçi metotlarla arttırdıklarında daha olumlu sonuçlara ulaşabileceklerini ortaya koymaktadır.

\section{KAYNAKLAR}

Ay, C., Ecevit, Z. 2005, “Çevre Bilinçli Tüketiciler”, Akdeniz iktisadi ve Idari Bilimler Fakültesi Dergisi, vol. 10, pp. 238-263.

Aziz, R.F. \& Hafez, S.M. 2013, "Applying lean thinking in construction and performance improvement", Alexandria Engineering Journal, vol. 52, pp. 679-695.

Bordean, ON., Borza, A. \& Glaser-Segura, D. 2011, "A Comparative Approach of the Generics Strategies Within The Hotel Industry: Romania VS. USA", Management \& Marketing Challenges fort he Knowledge Society, vol. 6, no. 4, pp.501-514.

Chavan, M. 2005, "An appraisal of environment management systems: A competitive advantage for small businesses", Management of Environmental Quality: An International Journal, vol. 16, no: 5, pp.444-463.

Chiarini, A. 2014, "Sustainable Manufacturing-Greening Processes Using Specific Lean Production Tools: An Empirical Observation From European Motorcycle Component Manufacturers", Journal of Cleaner Production, vol. 85, pp. 226-233.

Ertürk, H. \& Özçelik, F. 2008, “Yalın Üretim Uygulayan İşletmeler İçin Yalın Muhasebe”, Uludağ Üniversitesi Iktisadi ve Idari Bilimler Fakültesi Dergisi, vol. 27, no. 1, pp. 15-45.

King, A.A., Lenox, M.J. 2001, "Lean and Green An Empirical Examination Of The Relationship Between Lean Production And Environmental Performance", Production And Operations Management Society, vol. 10, no 3, pp. 244-256.

Lewis, A.M. 2000, "Lean production and sustainable competitive advantage", International Journal of Operations \& Production Management, vol. 20, no. 8, pp. 959-978. 